\title{
Researcher Mobility and Innovation: The Effect of Researcher Mobility on Organizational R\&D Performance in the Emerging Nations' Companies
}

\author{
Ayano Fujiwara ${ }^{1}$ \\ ${ }^{1}$ National Institute of Science and Technology Policy (NISTEP), Ministry of Education, Culture, Sports, Science \\ and Technology (MEXT), Japan \\ Correspondence: Ayano Fujiwara, National Institute of Science and Technology Policy (NISTEP), Ministry of \\ Education, Culture, Sports, Science and Technology (MEXT), Japan. Tel: 81-3-3581-2419. Email: \\ ayanokaayano@gmail.com
}

Received: April 14, 2018

Accepted: April 27, 2018

Online Published: May 22, 2018

doi:10.5539/ach.v10n2p36

URL: http://dx.doi.org/10.5539/ach.v10n2p36

\begin{abstract}
This study applies a knowledge production function to an empirical analysis of the relationship between innovation and the movement of knowledge workers. In the past, investments in R\&D and human resources were used as indices to measure innovation. However, this study analyzes the role that the movement of knowledge workers plays in innovation and the growth of the new corporations that recruited them from mature companies. This study reveals that the fluidity of talent and informal networks play an important role during the process of innovation. The analysis clearly shows that when innovation is measured by number of patents, the contribution of highly experienced and highly specialized researchers from developed countries is especially high. On the other hand, when innovation is measured by patent quality, both the number of researchers and the researchers' years of experience clearly exhibit positive effects.
\end{abstract}

Keywords: eigenvector centrality, knowledge production function, mobility, panel data, patent, R\&D

\section{Introduction}

This study is an empirical analysis of the effect of the movement of human resources on innovation (Griliches, 1990; Pakes \& Schankerman, 1984). As the influence of emerging nations on the world economy will increase in the future, an accompanying increase in the movement of knowledge workers from developed countries to emerging countries is quite likely. To this end, an empirical analysis was performed to study the types of researchers moving from developed countries to emerging countries who contributed to innovations in industries there.

So far, several models related to innovation have been presented, including those that use a knowledge production function to analyze the effect on innovation activities produced by human capital and investment in R\&D. Those studies focused on companies providing financial or human capital and obtaining knowledge capital in return. Exogenous business organizations that invested in capital and human resources are, in a way, models demonstrating the creation of innovation initiated by corporations.

To identify the relationship between knowledge workers and innovation, however, this study analyzes the type of contribution to innovation activities at new corporations provided by migrating knowledge workers who absorbed technology and knowledge from companies in developed countries. A number of indices representing the quality of the talent are established herein to analyze the role played by the movement of knowledge workers, which in turn creates the spillover of knowledge by these migrating researchers and influences the innovation and growth of their new companies. One of these indices is the social network index. Social networks are composed of different nodes of individuals and the social relationships that individually connect them. By observing the centrality index of each node, one can analyze the characteristics and roles of each node in the overall network. This analysis is carried out using data about researchers who migrated from developed countries to emerging nations to investigate what types of positions they held in their old companies to determine what they can contribute to innovation at their new workplace in a different country after their migration. In terms of the effect of talent migration on 
knowledge spillover via informal networks, no research data have been obtained. This study reveals that during the process of innovation the intervening fluidity of talent and informal networks plays an important role.

First, to analyze the characteristics of the talent who migrate from developed countries' corporations to those of emerging nations, a logistic regression model is used to verify the influence of basic explanatory variables such as inventors' individual social network index, career, and expertise on their migration. In particular, the corporations that achieved rapid growth by actively recruiting talent from developed countries might selectively employ these researchers. Therefore, the analysis is performed from the viewpoint of emerging nations' companies that recruit people from developed countries and is based on differences in priority characteristics, such as the career length, expertise, and excellence.

Second, the knowledge production function is applied to analyze what types of knowledge workers are contributing to innovation in emerging nations using panel data. Specifically, an empirical analysis is carried out to determine the quality of migrating talent who had worked at corporations in developed countries and their contribution to innovation at their new companies in emerging nations. Conventionally, R\&D expenditures have been used as indicators to measure innovation. However, in this study, an empirical analysis is performed to verify the influence of the quality of talent, migration, and embodied knowledge on innovation. In particular, to focus on the role played by a researcher's individual career in innovation at his/her new workplace in a foreign country, an analysis is carried out by establishing indicators to measure his/her career length, expertise, and excellence. Then, a calculation is performed using a fixed effects model and random effects model to analyze how migrating talent contributes to innovation in emerging nations.

As described above, this study quantitatively analyzes the relationship among social networks and the career change of individual researchers, mobility of talent, and innovation.

\section{Mobility of Knowledge Workers and Innovation}

Pakes and Griliches' (1984) work stands out among studies analyzing the influence of investment in R\&D and human capital. Studies by Hausman, Hall, and Griliches (1984), Hall, Griliches, and Hausman (1986), a relatively new study by Griliches (1990), Kortum and Lerner (1998), Crépon, Duguet, and Mairesse (1998), and Hall and Ham (1999) are also well known. These studies are analyses of patent data using the knowledge production function, considering the patent propensity in America and Europe and the patent productivity of R\&D using company-level data.

Figure 1 shows Griliches' (1990) knowledge production function relational diagram. In it, R represents the input factors of knowledge production, such as R\&D investment and the number of researchers; P represents another index displaying patents or the quantity of inventions; $\mathrm{K}$ represents the increase in economically valuable knowledge; $Z_{i}$ represents profit from increased knowledge; $X_{i}$ represents $Z_{i}=$ producing other input factors; $u_{i}$ and $\mathrm{w}_{\mathrm{i}}$ represent the disturbances in the process of creating a knowledge increase; and $\mathrm{v}_{\mathrm{i}}$ represents other factors that determine the quantity of disturbances and invention.

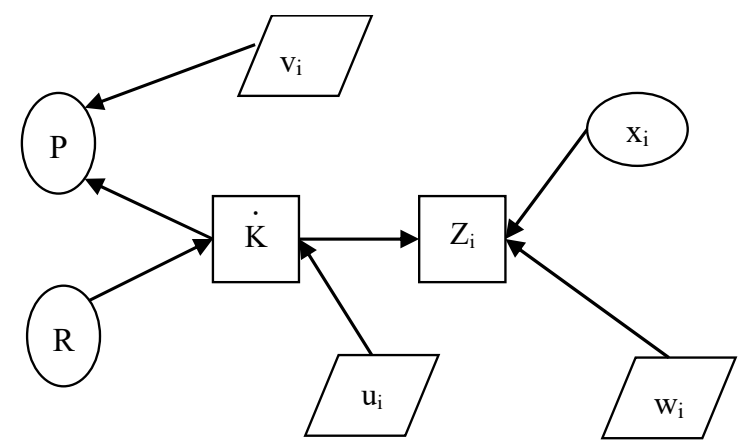

Figure 1. Knowledge Production Function: A Simplified Path Analysis Diagram

Source: Griliches (1990), Figure 13.3.

Conventionally, R\&D investment costs and number of patents have been widely used as surrogate variables for innovation. However, the size of R\&D costs is an input index and not an index to measure the output of innovation. Furthermore, the number of patents is used as an output index of innovation; however, the quality of the patent is also an important factor in addition to the number of patents. In this regard, patent quality has been studied and 
the number of times a patent has been cited (citation) has been proposed as a proxy for this purpose. Trajtenberg (1990), Jaffe, Trajtenberg, and Fogarty (2002), Reitzig (2003), and Hall, Jaffe, and Trajtenberg (2005) verified the strong correlation between the number of citations and the quality of patents. In addition, Carpenter et al. verified that the number of citations in the patents based on the inventions published in the annual IR100 list as remarkable technical innovations was higher than that of randomly sampled patents (Carpenter, Narin, \& Woolf, 1981). In addition, Harhoff, Narin, Scherer, and Vopel (1999) analyzed American and German patents and verified that the number of citations in the patents that were updated before expiration was greater than the number of patents that expired earlier. Based on the above, as an index to measure innovation, it important to consider the citation count in patents and the number of patents.

The relationship between the migration of talent and innovation is a less-researched field. However, it is anticipated that from now on a large number of knowledge workers will migrate from developed countries to emerging nations as the economic importance of the latter increases. Therefore, issues such as how such talent would contribute to innovation in emerging nations and what type of talent could contribute to that innovation are important. So far, in innovation analyses using the knowledge production function, the impact of R\&D investment and human capital on innovation has been analyzed. However, in this study, the impact of the quality of the talent who migrated from developed countries on innovation will be empirically analyzed. For specific analysis methods, the knowledge production function by Pakes and Griliches (1984) is used; for the explanatory variables, a patent citation count is used as a representative index to measure innovation by measuring the number and quality of the patents.

\section{Hypotheses}

In contrast to an analysis of the impact of $R \& D$ investment on innovation, such as by using the knowledge production function, this study analyzes the impact of the transfer of technology and knowledge on innovation in a corporation caused by the migration of knowledge workers who previously held positions at mature enterprises. For this analysis, first, the type of talent who migrate from developed countries' corporations to emerging nations' enterprises must be analyzed. Hence, the following hypothesis is advanced.

Hypothesis 1. What type of talent migrates from developed countries' enterprises to those of emerging nations?

To measure the characteristics of talent, various indices can be considered. However, from the viewpoint of contributions to innovation measured by the number or quality of patents, superiority as a researcher and whether the person was in a position where in-house technology and knowledge could be accumulated are important. Here, Hypothesis 1 is segmented into the two different hypotheses shown below to empirically analyze the question.

Hypothesis 1-1. Talent migrating from developed countries' corporations to emerging nations' enterprises were excellent personnel.

Hypothesis 1-2. Talent migrating from developed countries' corporations to emerging nations' enterprises used to hold higher positions.

In this way, an understanding of the characteristics of talented personnel migrating from developed countries' corporations to emerging nations' enterprises will lead to an analysis of what type of talent is being recruited by emerging nations' companies.

Next, an analysis is carried out by using Hypothesis 2 to determine whether talent recruited by emerging nations' corporations from developed countries contribute to innovation in their new host countries.

\section{Hypothesis 2. What type of talent contributes to the innovation of emerging nations'enterprises?}

As the recruited talent are expected to play leadership roles for local researchers with developing technology and knowledge in emerging nations' corporations, their rich experience and knowledge would have a strong impact. Therefore, the empirical analysis for Hypothesis 2 will be carried out on the basis of the two viewpoints shown below.

Hypothesis 2-1. Talent contributing to the innovation of emerging nations' enterprises were highly experienced.

Hypothesis 2-2. Talent contributing to the innovation of emerging nations' enterprises used to research in a specified technical field.

\section{Data and Variables}

\subsection{Data}

In this study, to analyze the innovation in the field of electrical appliances, patent data (1976-2013) from the H section of the IPC (International Patent Classification) is used. More specifically, approximately 260,000 US patent applications filed by companies in Japan, 50,000 applications filed by companies in South Korea, 7,000 
applications filed by companies in China, and 50,000 applications filed by companies in Taiwan and Hong Kong are used.

Using the automatic extraction program developed for this analysis, information such as the number of inventors, number of patents, number of patent citations, patent citation count, IPC number, and year of application was extracted from these patent data.

In Hypothesis 1, the analysis is based on the hypothesis that the rapidly growing companies are selectively recruiting talent from developed countries. The inventors who migrated from corporations in Japan to Samsung and other companies in South Korea and China were identified from the patent data filed by Japanese companies and other Asian companies. All the researchers' names listed as inventors of the patents mentioned above were extracted. Excluding the researchers with identical names, approximately 170,000 inventors belonged to Japanese companies and approximately 50,000 belonged to South Korean companies. Then, all the names of the inventors mentioned above who appeared both in patents filed by Japanese companies and those filed by non-Japanese companies were extracted. Since the researchers with identical names mentioned as inventors in Section $\mathrm{H}$ are highly likely to be the same person, the fact that their names appeared on patents filed by both Japanese and nonJapanese Asian companies means that these people have moved to a foreign country. However, even if the names are identical, some data may imply that they are different researchers. Therefore, certain conditions were set to eliminate these cases. Next, for the patents with the inventor's name that matched the one extracted as above, the company they belonged to was identified by examining the applications. Subsequently, considering the order of the years in which the applications were filed, the researchers' career change was identified by identifying which company they left and which company they then joined.

In Hypothesis 2, to analyze how developed countries' talent are contributing to the innovation of emerging nations' enterprises, 22 years (1990-2011) of patent data and financial data are used to perform an analysis with panel data pertaining to a Chinese corporation (Huawei), a Taiwanese corporation (Hon Hai), and three South Korean companies (Samsung, LG, and Hyundai).

\subsection{Explained Variable}

In Hypothesis 1, in order to determine what type of knowledge workers will migrate to emerging nations' enterprises, the explained variable can have two values: 1 for migrating to emerging nations' enterprises and 0 for not migrating.

In Hypothesis 2, the number of patents is used in this study. To measure the innovation of emerging nations' enterprises, when measuring the results of knowledge workers from developed countries' corporations, the production function employing the number of patents is used in this study. Many well-known studies have used the knowledge production function approach (Crépon et al., 1998; Griliches, 1990; Hall \& Ham, 1999; Hall et al., 1986; Hausman et al., 1984; Kortum \& Lerner, 1998; Pakes \& Griliches, 1984).

Furthermore, to measure the quality of patents, the citation count is also used as an explained variable because the analysis shows that the citation count of American patents (forward citation) is strongly correlated with the value of the patent in many cases (Hall et al., 2005; Jaffe et al., 2002; Reitzig, 2003; Trajtenberg, 1990). For example, Hall et al. (2005) demonstrated that the aggregation of the citation count of the patent owned by a corporation is correlated with the company's share price. Therefore, citation count can be an excellent index to verify the impact on the quality of the patents.

\subsection{Explanatory Variable}

In this study, to analyze the impact caused by the mobility of human resources and talent networks on the innovation of a corporation, a social network index and indices to measure the features of the talent are used as explanatory variables. Specifically, to measure the features of the migrating talent, variables such as the number of migrated inventors, the size of the company of origin, the number of career years, the citation count, the forward citation count, the Herfindahl-Hirschman Index of the IPC number, and eigenvector centrality are used.

In terms of the scale of the company of origin, corporations with $\$ 100$ trillion or greater sales are classified as large, whereas those with less than $\$ 100$ trillion sales are classified as small. The number of career years is calculated to be the number of years that elapsed from the year in which the inventor in question filed his/her first patent application. The patent citation count is used as a representative index to indicate patent quality. The total citation count of a patent in which the inventor in question has been involved is used as a surrogate index for his/her excellence. This approach has been validated by various studies (Carpenter et al., 1981; Harhoff et al., 1999); forward citation count is effective for measuring the quality of a patent, and an inventor involved in many high-quality patents can be regarded as excellent. Notably, as an index to measure patent quality, apart from the citation count, the number of 
backward citations of the patent correlates with the quality of the patent (Harhoff et al., 1999). From this, the number of times the patent is cited has also been added as a variable to measure the quality of talent.

In addition, the Herfindahl-Hirschman Index (HHI) of the IPC number can measure if an inventor has been involved with the patents of a specified technical domain or of varied technical domains. That is, a high HHI value indicates that the inventor has specialized in a specified technical field, whereas a low HHI value indicates that the inventor has wide knowledge covering varied technical fields. Eigenvector centrality is a centrality index proposed by Phillip Bonacich; it evaluates not only high-scoring nodes but also all nodes that are connected to high-scoring nodes. Being related to a node that has many relationships with other nodes implies an important position within the network.

In addition, a factor affecting the quality and quantity of the patent, apart from human resources, is the increase in the R\&D cost. Numerous studies (Crépon et al., 1998; Hall \& Mairesse, 1995; Hausman et al., 1984; Pakes \& Griliches, 1984) have analyzed the cost of R\&D and patent applications. In general, the number of patents can increase and their quality can improve if the R\&D cost is increased, regardless of the quality of researchers. Therefore, in this study, the R\&D cost of the current period is also used as a variable.

\section{Calculation Methods and Results}

\subsection{Testing the First Hypothesis: What Type of Talent Migrates from Developed Countries' Enterprises to those of Emerging Nations?}

To verify the characteristics of knowledge workers migrating to emerging nations' enterprises from developed countries' corporations, a logistic model is built for the analysis using two-value objective variables. The variables take the value 1 if the inventor migrated to an emerging nation and 0 if he/she did not. Explanatory variables such as the total of number of citings and citations of patents in which the inventor in the developed country has been involved in his/her career so far, the Herfindahl-Hirschman Index of the IPC, and eigenvector centrality are used.

The model formula is as follows.

$\mathrm{P}_{\mathrm{i}}(\mathrm{i}=1)=\mathrm{F}\left(\mathrm{C}+\sum \mathrm{a}_{\mathrm{i}} \mathrm{x}_{\mathrm{i}}\right)$

$\mathrm{P}_{\mathrm{i}}=\exp \left(\mathrm{C}+\sum \mathrm{a}_{\mathrm{i}} \mathrm{X}_{\mathrm{i}}\right) /\left(1+\exp \left(\mathrm{C}+\sum \mathrm{a}_{\mathrm{i}} \mathrm{X}_{\mathrm{i}}\right)\right)$

$\mathrm{P}_{\mathrm{i}}$ represents the probability that knowledge worker $i$ takes the value $1, \mathrm{~F}$ is the cumulative distribution function, $\alpha_{\mathrm{i}}$ is a coefficient, $\mathrm{X}_{\mathrm{i}}$ is an explanatory variable, and $\mathrm{C}$ is a constant. The analysis results are shown in Table 1.

Table 1. Logistic Regression: Knowledge Workers Migrating from Developed Countries' Corporations to Emerging Nations' Enterprises

\begin{tabular}{lcccc}
\hline \multirow{2}{*}{ Mobility of Knowledge Workers } & \multicolumn{2}{c}{ (1) Korean Companies } & \multicolumn{2}{c}{ (2) Taiwanese and Chinese Companies } \\
\cline { 2 - 5 } & Samsung & Other Companies & HonHai & Other Companies \\
\hline Backward citations per person & 0.0002748 & $0.0006454^{*}$ & 0.001248 & $0.000691^{*}$ \\
& $(0.72)$ & $(1.93)$ & $(0.55)$ & $(1.74)$ \\
Forward citations per person & $0.0013961^{* * *}$ & $0.0015431^{* * *}$ & -0.000980 & $0.001609^{*}$ \\
& $(3.14)$ & $(3.00)$ & $(-0.25)$ & $(2.46)$ \\
Company size & -0.3046282 & $-1.323645^{* * *}$ & $-1.97259^{* * *}$ & 0.650017 \\
& $(-1.1)$ & $(-4.60)$ & $(-3.12)$ & $(0.90)$ \\
Number of years of experience & 0.0005447 & 0.0001832 & $-0.061929^{*}$ & -0.000776 \\
& $(0.27)$ & $(0.06)$ & $(-1.91)$ & $(-0.23)$ \\
HHI of IPC number & -0.2013988 & 0.011731 & -0.530932 & 0.286130 \\
\multirow{2}{*}{ Eigenvector centrality } & $(-0.62)$ & $(0.02)$ & $(-0.76)$ & $(0.47)$ \\
& $2.8292350 * * *$ & $2.672211^{* * *}$ & $2.136945^{*}$ & 0.212661 \\
cons & $(6.19)$ & $(3.54)$ & $(1.64)$ & $(0.12)$ \\
& $-5.6093760^{* * *}$ & $-5.7875209^{* * *}$ & $-4.401456^{* * *}$ & $-7.58929^{* * *}$ \\
$\mathrm{~N}$ & $(-14.39)$ & $(-11.05)$ & $(-4.85)$ & $(-8.33)$ \\
\hline
\end{tabular}

*significant at the $10 \%$ level, ${ }^{* *}$ significant at the $5 \%$ level, $* * *$ significant at the $1 \%$ level.

According to the results, eigenvector centrality is significantly high. This result suggests that the emerging nations' companies preferred talent with high eigenvector centrality. The eigenvector centrality shows that these researchers tended hold important positions in corporations in developed countries. Thus, when emerging nations' companies are recruiting knowledge workers, it is supposed that an evaluation of the positions of the knowledge workers in the developed countries' corporations is used as one of the criteria. 
In addition, the result indicates that forward citations are significantly high in South Korean companies. This result suggests a high possibility that emerging nations' companies select new talent by considering the number of times the patent in question is cited, as it is the most commonly used index to indicate the importance of a patent.

Regarding the HHI index of the IPC number, while not statistically significant, negative values are preferred at a rapidly growing company such as Samsung and HonHai. This preference indicates the possibility that talent involved in patents in varied technical domains are preferred over researchers with a specified technical domain. On the other hand, the HHI index of the IPC number at the other companies shows positive values. This finding indicates that specialists in a specified technical field are preferred.

In contrast, the size of the company of origin, which is also statistically nonsignificant, can be regarded as not very important by recruiters in emerging nations seeking knowledge workers from developed countries. Hypothesis 11 and 1-2 are supported.

\subsection{Testing the Second Hypothesis: What Type of Talent Contributes to the Innovation of Emerging Nations' Enterprises?}

In this study, to verify the effectiveness of introducing knowledge workers from developed countries by companies in emerging nations such as China and South Korea, the knowledge production function advocated by Pakes and Shankerman (1984) and by Griliches and Regev (1995) is applied. The knowledge production function measures the effectiveness of R\&D investment to increase knowledge.

Griliches and Regev (1995) established the following formula to compare labor productivity between companies.

$$
\mathrm{Y}=\mathrm{Xb}+\mathrm{Zc}+\mathrm{lm}+\mathrm{u}
$$

Here, $\mathrm{Y}$ represents the logarithm of the productivity per worker, $\mathrm{X}$ is the logarithm of the input variable (intermediate inputs and capital services per person), and $\mathrm{Z}$ represents the control variables (e.g., dummy variables for size, age, and location). Griliches established eight variables: 1) intermediate inputs and fixed capital services, 2) R\&D capital and labor quality (as a proxy for human capital), 3) size, 4) sector and type of ownership, 5) industry grouping, 6) establishment year, 7) mobility status (entry and withdrawal status), and 8) year dummies.

In this study, the impact of the migration of knowledge workers from developed countries' corporations on innovation in emerging nations' enterprises is examined by entering the variable related to the characteristics of the knowledge worker. Usually, the number of patents is used as a surrogate variable for knowledge. The number of patents used as an explained variable is nonnegative numeric data. Hall and Mairesse (1995), Mairesse and Hall (1996), and Harhoff (1998) analyzed French, US, and German manufacturers using the fixed effects model to control the deviation of a company's fixed effect. In this study, the fixed effects model and random effects model are used to perform calculations following the example of Hausman et al. (1984). The calculation results are shown in Table 2.

Formula (1) of Table 2 shows the result calculated using the fixed effects model. From the calculation results, the maximum impact on the innovation of emerging nations' enterprises measured by the number of patents is caused by the number of researchers belonging to the company. The number of migrating talent from developed countries is positive but small and statistically nonsignificant. This result suggests that the talent from developed countries slightly affects the number of patents. Moreover, the statistically nonsignificant coefficient of eigenvector centrality is small, demonstrating that important positions held by the migrating talent from developed countries' corporations are irrelevant to the talent's contribution to the innovation of emerging nations' enterprises. On the other hand, the HHI of the IPC number is positive, suggesting a high possibility of contribution to the innovation of emerging nations by talent who have conducted research in a specified technical field.

Formula (2) has been calculated using a random effects model. For the number of patents, the coefficient of local labor number is positive, whereas the number of developed countries' researchers is positive but small. Therefore, an increased number of researchers from developed countries may not necessarily contribute to an increase in the number of patents created by emerging nations' enterprises. On the other hand, the coefficient of the number of years of experience is positive; this suggests that senior researchers from developed countries may be contributing to the increase in the number of patents of emerging nations' enterprises. In addition, the coefficient of HHI of the IPC number is positive; this result suggests that the researchers who have worked in a specified technical field contribute more to the increased number of patents than do the talent who worked in varied fields.

Two methods, namely, the fixed effects model and random effects model, are used in this calculation. The null hypothesis can be dismissed in the Hausman test because of the selection of the two calculation methods. Therefore, as a result, the fixed effects model is preferable. 
Table 2. Impact Caused by the Migration of Knowledge Workers from Developed Countries on the Innovation of Emerging Nations' Enterprises

\begin{tabular}{|c|c|c|c|c|}
\hline \multirow[t]{2}{*}{ Patent } & \multicolumn{2}{|c|}{ (1) Fixed effect } & \multicolumn{2}{|c|}{ (2) Random effect } \\
\hline & $-0.68423^{* * *}$ & $(-3.76)$ & $0.055439 * * *$ & (3.16) \\
\hline \multicolumn{5}{|c|}{ Characteristics of knowledge workers from developed countries } \\
\hline Migrated labor number & 0.034616 & $(0.70)$ & $-0.170241 * *$ & $(-2.42)$ \\
\hline HHI of IPC number & 0.156153 & $(1.50)$ & $0.37986^{* *}$ & $(2.02)$ \\
\hline Company size & -0.015197 & $(0.646)$ & -0.037986 & $(-0.64)$ \\
\hline Backward citation & -0.013331 & $(-0.44)$ & 0.016126 & $(0.30)$ \\
\hline Forward citation & 0.001636 & $(0.05)$ & -0.023300 & $(-0.41)$ \\
\hline Number of years of experience & 0.11737 & $(0.19)$ & -0.0962001 & $(-0.84)$ \\
\hline Eigenvector centrality & 0.011737 & $(0.19)$ & -0.002954 & $(-0.19)$ \\
\hline \multicolumn{5}{|c|}{ Characteristics of knowledge workers from developing countries } \\
\hline Labor number & $0.9034218 * * *$ & $(13.75)$ & $0.667559 * * *$ & $(8.63)$ \\
\hline Backward citation & 0.082151 & $(1.63)$ & $0.1811539^{* * *}$ & (3.06) \\
\hline Forward citation & 0.22882 & $(0.49)$ & $0.117014 * * *$ & $(2.92)$ \\
\hline \multicolumn{5}{|l|}{ Scale $($ ref. $=$ small size $)$} \\
\hline Middle size & 0.022208 & $(0.40)$ & -0.063399 & $(-0.72)$ \\
\hline Large size & 0.069359 & $(0.62)$ & -0.079676 & $(-0.52)$ \\
\hline \multicolumn{5}{|l|}{ Life cycle (ref.=less 20 years) } \\
\hline From 20 to 40 years & $0.173629 * *$ & $(2.29)$ & 0.174364 & (1.54) \\
\hline Over 40 years & -0.066178 & $(-0.61)$ & 0.065237 & $(0.51)$ \\
\hline cons & 0.18295 & $(0.47)$ & $-9.1473 * *$ & $(-2.52)$ \\
\hline Year dummy & \multirow{2}{*}{\multicolumn{2}{|c|}{ yes }} & \multicolumn{2}{|l|}{ yes } \\
\hline Hausman test & & & \multicolumn{2}{|l|}{0.0000} \\
\hline
\end{tabular}

*significant at the $10 \%$ level, $* *$ significant at the $5 \%$ level, $* * *$ significant at the $1 \%$ level.

Table 3. Impact of the Migration of Knowledge Workers from Developed Countries on the Innovation of Emerging Nations' Enterprises

\begin{tabular}{|c|c|c|c|c|}
\hline \multirow{2}{*}{$\begin{array}{r}\text { Forward citation } \\
\text { R\& D cost }\end{array}$} & \multicolumn{2}{|c|}{ (1) Fixed effect } & \multicolumn{2}{|c|}{ (2) Random effect } \\
\hline & \multicolumn{2}{|c|}{$0.002772 \quad(0.04)$} & \multicolumn{2}{|c|}{$0.284159 * * * \quad(5.41)$} \\
\hline \multicolumn{5}{|c|}{ Characteristics of knowledge workers from developed countries } \\
\hline Migrated labor number & $0.601678 * * *$ & $(4.16)$ & 0.409210 & $(1.52)$ \\
\hline HHI of IPC number & -0.10717 & $(-0.29)$ & -0.684964 & $(-0.95)$ \\
\hline Company size & -0.003446 & $(-0.03)$ & -0.363942 & $(-1.60)$ \\
\hline Backward citation & -0.062008 & $(-0.57)$ & -0.280712 & $(-1.37)$ \\
\hline Forward citation & -0.093417 & $(-0.77)$ & 0.238784 & $(1.08)$ \\
\hline Number of years of experience & 0.160971 & $(0.72)$ & $0.924790 * *$ & $(2.17)$ \\
\hline Eigenvector centrality & 0.027560 & $(0.86)$ & $0.129107 * *$ & $(2.24)$ \\
\hline \multicolumn{5}{|c|}{ Characteristics of knowledge workers from developing countries } \\
\hline Labor number & $0.779671 * * *$ & $(3.98)$ & $0.486853 *$ & $(1.65)$ \\
\hline Backward citation & -0.161082 & $(-0.90)$ & 0.249539 & $(1.08)$ \\
\hline \multicolumn{5}{|l|}{ Scale (ref.=small size) } \\
\hline Middle size & $-0.51931 * * *$ & $(-2.93)$ & $-1.38836 * * *$ & $(-0.52)$ \\
\hline Large size & $-1.87767 * * *$ & $(-7.56)$ & $-2.69646^{* * *}$ & $(-6.26)$ \\
\hline \multicolumn{5}{|l|}{ Life cycle (ref. $=$ less 20 years) } \\
\hline From 20 to 40 years & $-0.738902 * * *$ & $(-3.05)$ & -0.231894 & $(-5.22)$ \\
\hline Over 40 years & $-1.20232 * * *$ & $(-0.36)$ & $-0.864581^{*}$ & $(-1.78)$ \\
\hline _cons & $5.89562 * * *$ & $(5.86)$ & -2.19352 & $(-1.58)$ \\
\hline Year dummy & yes & & yes & \\
\hline Hausman test & & & 0.0232 & \\
\hline
\end{tabular}

*significant at the $10 \%$ level, $* *$ significant at the $5 \%$ level, $* * *$ significant at the $1 \%$ level 
One of the major contributions of this study is that it demonstrates that the senior researchers or inventors working in a specified field among the talent who migrated from developed countries are highly likely to contribute to the innovation measured by the number of patents filed by emerging nations' companies.

Next, Table 3 shows the results using the number of cited patents as an index to measure innovation. The number of patents has been used as an index to measure innovation in many studies (Pakes \& Griliches, 1984). However, it cannot be concluded that only a high number of patents is good for innovation; inventing high-quality patents is also important.

The calculation results are as follows.

Formula (1) of Table 3 is the result calculated using the fixed effects model. This result suggests that there is a significant contribution from the talent of developed countries to the innovations measured by the quality of patents. The HHI of the IPC number is negative, suggesting a high possibility of contribution to the innovation of emerging nations by talent who have conducted research in varied technical fields. In addition, although not statistically significant, eigenvector centrality is positive. This result suggests that talent who used to hold important positions in developed countries' corporations may be contributing to an improvement in the quality of patents.

Furthermore, formula (2) of Table 3 shows the result calculated using the random effects model. Regarding the quality of patents, the number of years of experience in developed countries' corporations shows significant effectiveness in increasing the quality of patents. In addition, the eigenvector centrality is positive. This result suggests that the knowledge workers in important positions in the developed countries' corporations contribute to innovation. Thus, in terms of innovation measured by the quality of patents, the number of researchers and their years of experience in corporations in developed countries evidently show positive effects. The null hypothesis can be dismissed in the Hausman test due to the selection of the two calculation methods. Therefore, the fixed effects model is preferable.

The results of the analysis of innovation measured by the number and quality of patents show that the migrating talent from developed countries contribute to innovations as measured by the quality of patents rather than to innovations measured by the number of patents. On the other hand, senior researchers contributed to the increase in the number of patents and the quality of patents. Moreover, the statistically nonsignificant coefficient of former company size is negative for innovations measured by the quality of patents and for innovations measured by the number of patents. Hypothesis 2-1 is supported.

The negative coefficient of R\&D costs probably results from the fact that the objects of analysis in this study are emerging nations' companies; their R\&D investment has not yet effectively produced innovation.

\section{Conclusion and Implications}

As shown above, this study empirically analyzed the relationship between the migration of human resources and innovation from the viewpoint of the characteristics of inventors and informal networks. The analysis suggests that in emerging nations that have achieved rapid growth, excellent researchers in important positions from advanced countries' corporations are selectively recruited.

On the other hand, when the innovation of emerging nations' corporations is measured by number of patents, it becomes clear that senior researchers and highly specialized inventors among the talent from companies in developed countries have contributed significantly. In addition, if the innovation of emerging nations' enterprises is measured by the quality of their patents, it becomes clear that innovations are better facilitated by higher numbers of talented individuals from developed countries' corporations; specifically, the contribution to innovation is greater from those who have conducted research in varied technical fields and have had longer careers.

Going forward, as emerging nations achieve further economic growth, the size of their local companies will grow, and the standards of their local education and economy will improve; further talent mobility between emerging and developed countries is expected. For emerging nations in Asia or elsewhere, when a company creates innovation, it is essential for it to optimize the technology and knowledge from developed countries' corporations and the knowledge workers who embody them. In this study, only an analysis of Chinese and South Korean enterprises was conducted. However, in terms of the relationship between innovation and talent migration, expansion of the scope of analysis to all Asian countries would be useful for further study.

\section{Acknowledgments}

I am grateful to Prof. Toshiya Watanabe (the University of Tokyo) who provided many suggestions and comments on a previous version of this paper. 


\section{Funding}

This work was supported by JSPS KAKENHI Grant Number 16K13383.

\section{References}

Carpenter, M. P., Narin, F., \& Woolf, P. (1981). Citation rates to technologically important patents. World Patent Information, 3(4), 160-163. https://doi.org/10.1016/0172-2190(81)90098-3

Crépon, B., Duguet, E., \& Mairesse, J. (1998). Research, innovation and productivity: An econometric analysis at the firm level. Economics of Innovation and New Technology, 7(2), 115-158. https://doi.org/10.1080/104 38599800000031

Griliches, Z. (1990). Patent statistics as economic indicators: A survey. Journal of Economic Literature, 28(4), 1661-1707. https://doi.org/10.3386/w3301

Griliches, Z., \& Regev, H. (1995). Productivity and firm turnover in Israeli industry: 1979-1988. Journal of Econometrics, 65(1), 175-203. https://doi.org/10.1016/0304-4076(94)01601-U

Hall, B., \& Ham, R. (1999). The patent paradox revisited: Determinants of patenting in the U.S. semiconductor industry 1980-94. NBER Working Paper No. W7062.

Hall, B. H., Griliches, Z., \& Hausman, J. A. (1986). Patents and R and D: Is there a lag? International Economic Review, 27(2), 265-283. https://doi.org/10.2307/2526504

Hall, B. H., Jaffe, A., \& Trajtenberg, M. (2005). Market value and patent citations. The RAND Journal of Economics, 36(1), 16-38.

Hall, B. H., \& Mairesse, J. (1995). Exploring the relationship between R\&D and productivity in French manufacturing firms. Journal of Econometrics, 65(1), 263-293. https://doi.org/10.1016/0304-4076(94)01604-X

Harhoff, D. (1998). R\&D and productivity in German manufacturing firms. Economics of Innovation and New Technology, 6(1), 29-50. https://doi.org/10.1080/10438599800000012

Harhoff, D., Narin, F., Scherer, F. M., \& Vopel, K. (1999). Citation frequency and the value of patented inventions. The Review of Economics and Statistics, 81(3), 511-515. https://doi.org/10.1162/003465399558265

Hausman, J., Hall, B. H., \& Griliches, Z. (1984). Econometric models for count data with an application to the patents-R \& D relationship. Econometrica, 52(4), 909-938. https://doi.org/10.2307/1911191

Jaffe, A., Trajtenberg, M., \& Fogarty, M. (2002). The meaning of patent citations: Reports on the NBER/casewestern reserve survey of patentee. In A. Jaffe \& M. Trajtenberg (Eds.), Patents, citations and innovations. Cambridge, MA: The MIT Press.

Kortum, S., \& Lerner, J. (1998). Stronger protection or technological revolution: what is behind the recent surge in patenting? Carnegie-Rochester Conference Series on Public Policy, 48, $247-304$. https://doi.org/10.1016/S0167-2231(98)00023-2

Mairesse, J., \& Hall, B. H. (1996). Estimating the productivity of research and development: an exploration of GMM methods using data on French \& United States manufacturing firms. National Bureau of Economic Research Working Paper no. 550

Pakes, A., \& Griliches, Z. (1984). Estimating distributed lags in short panels with an application to the specification of depreciation patterns and capital stock constructs. The Review of Economic Studies, 51(2), $243-262$. https://doi.org/10.2307/2297690

Pakes, A., \& Schankerman, M. (1984). The rate of obsolescence of patents, research gestation lags, and the private rate of return to research resources. In Z. Griliches (Ed.), R\&D, patents, and productivity (pp. 73-88). Chicago, Illinois: University of Chicago Press.

Reitzig, M. (2003). What determines patent value?: Insights from the semiconductor industry. Research Policy, 32(1), 13-26. https://doi.org/10.1016/S0048-7333(01)00193-7

Trajtenberg, M. (1990). A penny for your quotes: Patent citations and the value of innovations. The RAND Journal of Economics, 21(1), 172-187. https://doi.org/10.2307/2555502

\section{Copyrights}

Copyright for this article is retained by the author(s), with first publication rights granted to the journal.

This is an open-access article distributed under the terms and conditions of the Creative Commons Attribution license (http://creativecommons.org/licenses/by/4.0/). 